INVESTIGACIONES

de HISTORIA ECONÓMICA

2007, invierno, número 7. Pp. 101 a 130

\title{
¿Misión imposible?: La expropiación de las empresas alemanas en España (1945-1975)
}

\section{Mission: Impossible? The Expropriation of German Business Assets in Spain} (1945-1975)

\author{
NÚRIA PUIG RAPOSO \\ Universidad Complutense de Madrid \\ ADORACIÓN ÁLVARO MOYA \\ Universidad de Barcelona
}

\begin{abstract}
RESUMEN
Este trabajo se ocupa de una cuestión clave en el desarrollo económico de la periferia europea:

la relación entre inversión extranjera y nacionalismo económico. La investigación se centra en el proceso de bloqueo, expropiación

y recompra de las empresas alemanas radicadas en España, que tuvo lugar entre 1945 y 1975 y que se reconstruye siguiendo la pista de los implicados: las compañías foráneas y sus socios locales, las empresas españolas interesadas en sus activos, las administraciones hispana y alemana, y la Comisión del Control Aliado. En el artículo se demuestra que, a corto y medio plazo, la expropiación creó oportunidades de negocio extraordinarias para los socios tradicionales de los alemanes y para

la banca industrial del país. A largo plazo, empero, los acuerdos privados entre las matrices alemanas y sus socios españoles permitieron a los antiguos propietarios, en general, mantener el control de sus empresas y fortalecer su posición en España.
\end{abstract}

PALABRAS CLAVE: Inversión extranjera, Nacionalismo económico, Bienes alemanes, Expropiación, España contemporánea

\section{ABSTRACT}

This article deals with a key issue in the economic development of the European periphery: the relationship between foreign investment and economic nationalism. The research focuses on the process of blockade, expropriation and reacquisition of German assets in Spain, which took place from 1945 to 1975. The process has been reconstructed by tracking its main characters: the German companies and their local partners, the Spanish groups interested in acquiring them, the Spanish and the German administrations, and the Allied Control Council. Our study reveals that, in the short run, the expropriation programme originated great business opportunities for the traditional partners of the German firms as well as for Spanish industrial banking. In the long run, however, due to private contracts between them and the German headquarters, the process allowed old owners to keep control of their assets and strengthen their position in the Spanish market.

KEY WORDS: Foreign investment, Economic nationalism, German business assets, Expropriation, Contemporary Spain

JEL Codes: F23, N44, N84, O12 


\section{Introducción ${ }^{1}$}

$\mathrm{L}$

a industrialización española, como la de muchos países de la periferia europea, tuvo lugar bajo el signo de la influencia extranjera y del nacionalismo económico. Este trabajo se propone entender cómo estas dos fuerzas, aparentemente contradictorias, actuaron en una etapa fundamental de la modernización social y económica del país. Para ello se ha examinado el proceso de bloqueo y expropiación de las empresas alemanas, que se abrió con la adhesión del gobierno español a los acuerdos de Bretton Woods en 1945 y que no se cerraría oficialmente hasta finales de los años cincuenta. El capital y la tecnología germanos habían desempeñado un papel primordial en el arranque de la segunda revolución industrial en nuestro país, de tal modo que, en 1945, resultaban vitales en sectores como la química y la electrotecnia. En la medida en que la voluntad de los Aliados de desactivar el potencial económico de Alemania en los países neutrales (programa Safehaven) significaba que propiedades industriales de primer orden podrían pasar a manos españolas, el proceso ofrecía una oportunidad excepcional a los ideólogos de la autarquía y a los grupos empresariales nacionales mejor situados en los planos técnico, financiero y político.

¿Fue realmente así? Nuestra investigación demuestra que sólo parcial y temporalmente, pues tanto los expertos de la Comisión de Expropiación de Bienes Extranjeros, encargada de la expropiación, como los empresarios españoles que acudieron a los concursos de adjudicación, eran conscientes de que no podía prescindirse de la colaboración de las matrices alemanas. Ello permitió a los antiguos propietarios mantener, a largo plazo, el control de sus empresas y fortalecer su posición en España. Nuestro trabajo corrobora así la tesis, sostenida recientemente por Collado y Martín Aceña, de que la diplomacia económica española gestionó con habilidad el programa Safehaven ${ }^{2}$. Pero demuestra, además, que fueron los acuerdos privados entre las matrices alemanas y sus viejos y nuevos socios españoles los que preservaron los intereses de ambas partes, generando a corto y medio plazo oportunidades de negocio extraordinarias para los segundos. El papel de los Aliados y de la diplomacia de la República Federal de Alemania, por el contrario, fue menor. En el período de la historia de España en que más ha primado la política sobre la economía, la influencia extranjera (representada por intereses económicos privados alemanes y españoles) fue más poderosa que el nacionalismo económico oficial.

[Fecha de recepción del original, enero de 2006. Versión definitiva, septiembre de 2006]

1 Esta investigación se ha realizado en el marco del proyecto del Ministerio de Educación y Ciencia BEC20038455. Agradecemos a los responsables de los archivos consultados la ayuda ofrecida, así como a los evaluadores de Investigaciones de Historia Económica sus comentarios. Los errores que permanezcan son de nuestra exclusiva responsabilidad.

2 Collado (2001) y Martín Aceña, con otros (2001). 
El artículo reconstruye los intereses económicos alemanes en España hasta el final de la II Guerra Mundial (apartado 2) y el proceso de bloqueo y expropiación de las empresas germanas (apartado 3), para poder evaluar los efectos de dicho proceso a corto (apartado 4) y largo plazo (apartado 5). En el centro del análisis se sitúan las estrategias desarrolladas por los distintos agentes del proceso.

\section{La influencia económica de Alemania en España antes de 1945}

La España de la Restauración fue uno de los escenarios de la lucha de las grandes potencias por alcanzar o por mantener la hegemonía política y económica mundial. En el marco de la segunda oleada industrializadora y de una internacionalización de la economía sin precedentes, Alemania pasó a ser una de esas potencias.

El capital germano probó suerte, primero, en la minería, donde se asoció, o más bien se subordinó, a las compañías francesas y británicas, que controlaban el sector desde hacía décadas ${ }^{3}$. Menos restricciones presentaron los sectores en los que se fundamentaba el liderazgo científico-técnico alemán. Allí las inversiones se hicieron en solitario ${ }^{4}$. Las primeras en llegar, y en crear una pauta, fueron las compañías electrotécnicas. Consistiría esa pauta en crear sociedades con nombre, sede, socios y presidentes españoles, identificadas con los objetivos proteccionistas de los industriales nacionales, pero controladas plenamente desde Alemania. Por ella se rigieron AEG (1901, Allgemeine Elektrizitätsgesellschaft) y Siemens (1910). Ambas constituirían poco más tarde Osram, Fábrica de Lámparas (1914, hasta 1921 Fábrica de Lámparas de Filamento Metálico). Si exceptuamos la Electro-Química de Flix (1897, aliada muy pronto a la empresa catalana $(r o s)$, las inversiones químicas, el otro buque insignia de la capacidad de innovación de la nueva industria alemana, fueron en cambio más bien modestas, pues lo que más interesaba a las matrices era exportar y ofrecer un buen servicio a los clientes ${ }^{5}$.

El nacionalismo industrial que intensificó la ley de 1917 sobre defensa de la industria nacional, junto con el tratado comercial de 1926 -oficialmente vigente hasta los años cincuenta-, facilitaron un mayor acercamiento económico entre ambos países. A ello también contribuyeron las dificultades de la República de Weimar, que empujaron a un buen número de alemanes, comerciantes y profesionales, a emigrar. En 1923 se creó la Cámara de Comercio Alemana para España, una de las instituciones que más actividad y continuidad ha tenido en la historia de las relaciones

Loscertales (2002).

Pero con el firme apoyo de la diplomacia alemana. Bundesarchiv (BA), R/901-2231, 2235 y 41800.

Puig y Loscertales (2001). 
económicas hispano-alemanas y de la colonia alemana en España ${ }^{6}$. El entramado empresarial hispano-alemán, mientras, se robusteció de manera notable a través de nuevas alianzas y nuevas personalidades. El sector químico nos proporciona algunos ejemplos, como el de Josep Pellicer, antiguo proveedor del ejército español en Marruecos y futuro "hombre de los alemanes" en la España autárquica. Pellicer fue el artífice de una de las empresas más interesantes de esta época, Fabricación Nacional de Colorantes y Explosivos (FNCE), además de pieza clave del Banco Alemán Trasatlántico (BAT), entidad que canalizaba buena parte de la inversión alemana ${ }^{7}$.

Entre la sublevación nacionalista de 1936 y la derrota de la Alemania nazi en 1945, la influencia económica de Alemania en España alcanzó máximos. Esa influencia se manifestó en tres planos: el control del comercio exterior, el desarrollo de una base productiva autónoma en España y la creación de "activos" en forma de deudas de guerra con los que se pretendía financiar la inversión directa alemana ${ }^{8}$. Estos activos, reclamados por los alemanes en el curso de las negociaciones sobre el bloqueo y la expropiación, dieron lugar a un conflicto diplomático entre los dos países que se extendería hasta mucho después de concluida la II Guerra Mundial. De los dos primeros objetivos se ocuparon, desde 1936, dos organismos creados ad hoc, la Hisma (Compañía Hispano-Marroquí de Transportes Limitada, Sofindus desde 1938) y la Rowak (Rohstoff-Waren Kompensation Handelgesellschaft GmbH). El gobierno español, de acuerdo con los Aliados, disolvería ambos tras la guerra. Los resultados del proyecto alemán fueron, sin embargo, muy limitados, reduciéndose a la extracción y exportación de minerales de interés bélico y al contrabando de guerra9 ${ }^{9}$. A ello había contribuido el nacionalismo económico franquista, aplaudido y manipulado por empresarios como Federico Lipperheide, comerciante alemán dedicado desde 1921 a la explotación y exportación de minerales a través de Somimet (Sociedad Bilbaína de Minerales y Metales $S A)^{10}$. Sus intereses chocaron frontalmente con la nueva maquinaria comercial nazi, dirigida por un personaje relativamente nuevo en la colonia alemana en España, Johannes Bernhardt ${ }^{11}$. Fuentes muy diversas apuntan que, para

6 Actas y boletines de la Cámara en Deutsche Handelskammer für Spanien Madrid (DHK MAD); Politisches Archiv des Auswärtiges Amts Berlin (AA), B26-43; y Puig (2005).

Puig (1999), (2003) y (2004).

Viñas (2001), García Pérez (1994) y Leitz (1996).

Si bien los intercambios, en su conjunto, se vieron muy favorecidos por el largo período bélico iniciado en 1936. La novedad no estribaba tanto en el hecho de que la Alemania nazi se convirtiera en el primer suministrador de bienes industriales, sino en el papel desempeñado por España para sostener el esfuerzo bélico con sus alimentos, minerales y otras materias primas. Viñas (2001); García Pérez (1994); Leitz (1996); Martín Aceña (2001); Estadística del Comercio Exterior de España (1940-1945), y Statistisches Reichsamt (19361938).

Puig (2006).

Viñas (2001), pp. 308-312. 
frenar la competencia del empresario vasco-alemán, Bernhardt acusó a Lipperheide de trabajar para los Aliados, denuncia que obligó a este último a sellar un acuerdo con el poderoso Bernhardt.

Incorporar socios y testaferros españoles fue, por otro lado, un recurso habitual entre las empresas alemanas para eludir el nacionalismo industrial de la posguerra española. Muchos de los alemanes con más antigüedad en el país, además, adoptaron la nacionalidad española, lo que les permitía sustraerse a la legislación de 1939 y, así, ocupar posiciones clave en las filiales o crear empresas españolas de interés nacional. Entre los mejores ejemplos de lo primero se encuentra Fernando Birk, figura de referencia de la química alemana en España entre el estallido de la Guerra Civil y su jubilación en $1967^{12}$. Entre quienes optaron por lo último figura el ya mencionado Lipperheide. Ni Birk, con quien se enfrentó por el uso de las licencias de la IG Farben, ni los Aliados pudieron impedir que, con el apoyo técnico y financiero de socios muy diversos (alemanes y españoles) fundara sociedades tan importantes (y calificadas de interés nacional) como Unquinesa, Sefanitro, Hidro-Nitro, Nitratos de Castilla o Agra entre 1939 y $1945^{13}$.

El Cuadro 1 recoge las sociedades germanas más relevantes presentes en el tejido empresarial español al acabar la II Guerra Mundial. La inversión alemana, desde finales del siglo XIX, había ido concentrándose en cuatro sectores: química, electrotecnia, banca y seguros. En los dos primeros gozaba de una importante posición de mercado, reforzada durante las guerras española y mundial ${ }^{14}$, pero los intereses alemanes no eran particularmente fuertes en los sectores de banca y seguros, con algunas notables excepciones ${ }^{15}$. Con todo, las aseguradoras y la banca germanas servían a la industria y a las redes comerciales hispano-alemanas, en algunos casos con carácter monopolístico. Nótese, además, que algunas empresas (Inquiresa, Behring, Química Española, Tarsia, Construcciones Industriales y Telefunken, fundada por AEG y Siemens) y las ampliaciones de algunos grupos (AEG con la compra de Electra Industrial de Tarrasa y Eléctrica de Rubî) nacieron en tiempos de guerra.

12 La trayectoria de Birk, empleado de Bayer en España desde 1926, en Bayer Archiv Leverkusen (BAL), Personalia; y National Archives and Records Administration (NARA), Record Group (RG)226/ Entry (E)19/Box (B)203/Report (R)13978. Birk fue, entre otras muchas cosas, presidente de la Cámara de Comercio Alemana de 1945 a 1950, cuando fue la única activa en el mundo. DHK MAD, actas 1949-1950.

13 Puig (2006). NARA, RG226/E19/B3/File (F) 16/R165726.

$14 \quad$ El poder de mercado de las filiales químicas españolas puede estimarse en un 80 por 100 en vísperas de la Gran Guerra. Archivo del Ministerio de Asuntos Exteriores (AMAE) R4316/4 y R4209/7. Por volumen de activos, Siemens, AEG y Osram ocupaban en 1934 los puestos 9, 15 y 16, respectivamente, y Geathom, donde participaba AEG, el segundo. Anuario Financiero y de Sociedades Anónimas (AFSA) (1934/35). Ahora bien, algunos segmentos de este mercado (muy cartelizado) eran controlados, directa o indirectamente, por las casas alemanas. NARA, RG 226/E19/B86/RXL6050, AMAE, R4303/6 y las fuentes del Cuadro 1.

15 En 1934, tan sólo el Banco Germánico se encontraba entre las 20 primeras entidades bancarias por volumen de activos. AFSA, (1934/35). Entre las aseguradoras destacaban la Victoria de Berlín y Plus Ultra. Pons (2002), pp. 82 y 96. La otra sociedad importante desde 1935 fue La Constancia. Frax y Matilla (1998), p. 6. 


\section{El proceso de liquidación de los bienes alemanes, 1945-1958}

El proceso de bloqueo, expropiación y nacionalización de los bienes alemanes en España, desarrollado entre 1948 y 1958, lastraría de un modo extraordinario y sin precedentes las relaciones diplomáticas hispano-alemanas, tradicionalmente buenas y con un sólido respaldo económico y cultural ${ }^{16}$. Si bien España se adhirió a las resoluciones de Bretton Woods ya en 1945, el tratado que dio luz verde al proceso de bloqueo - firmado con Estados Unidos, Gran Bretaña y Francia- no se cerró hasta mayo de 1948. Con ello, España quedaba integrada, como Portugal, Suecia y Suiza, en el programa Safehaven de los Aliados (dirigido por el Consejo de Control Aliado, CCA), diseñado para desactivar el potencial bélico alemán en los últimos meses de la guerra y financiar la reconstrucción posbélica ${ }^{17}$.

La expropiación de empresas privadas formó parte de un proceso más amplio que afectó al conjunto de las propiedades, públicas y privadas, industriales e inmobiliarias, de Alemania en el extranjero ${ }^{18}$. Para el caso español, los Aliados, en lugar de un pago global por el valor de todas las propiedades alemanas, aceptaron desglosar el proceso entre bienes públicos y privados, y percibir, por los segundos, el 76 por 100 de su valor (o justiprecio) de forma gradual según se iban adjudicando vía concurso público. De su gestión se encargó la Comisión de Expropiación de Bienes Extranjeros (CEBE, creada en julio de 1948), dependiente del Ministerio de Asuntos Exteriores y cuyas decisiones debían ser ratificadas por el Consejo de Ministros. Tanto la definición de los mecanismos del proceso como la identificación de las propiedades consumieron mucho tiempo, que fue aprovechado por los propietarios para camuflar sus intereses, total o parcialmente ${ }^{19}$, o para buscar otras soluciones con el auxilio de aliados útiles en España. Un convenio firmado entre España y la nueva República Federal de Alemania el 8 de abril de 1958, ratificado cuatro meses más tarde por los Aliados, permitió la normalización de las relaciones entre los dos países. La actividad de la CEBE, no obstante, llevaba paralizada desde el verano de 1952, ante la negativa de la RFA a reconocer el tratado firmado con los Aliados cuatro años antes ${ }^{20}$. Los expedientes en proceso de tramitación por aquel entonces quedaron "en suspenso".

16 Delaunay (1989), Weber (1992), Collado (2001) y (2005).

17 El programa Safehaven se reguló en virtud de la Resolución VI, aprobada en julio de 1944. US Department of State (1997), pp. 18-19. En esta investigación se han utilizado los informes realizados por los servicios de inteligencia aliados encargados de dicho programa (depositados en NARA).

18 US Department of State (1997) y (1998).

19 Véase la cuarta columna del Cuadro 1.

20 Aceña con otros (2001), pp. 173-174. 
Collado coincide con los diplomáticos alemanes contemporáneos en que España, de la mano del diplomático Emilio de Navasqüés, presidente de la CEBE, jugó muy bien sus cartas, tanto con los alemanes como con los Aliados ${ }^{21}$. ¿Cuál era el objetivo español? Ganar tiempo para evitar la desactivación, no ya del potencial económico alemán, sino de la economía española, muy dependiente de los activos alemanes en dos sectores clave. De ahí la firme determinación de la CEBE de incluir patentes y marcas en los activos a expropiar y de que, en la medida de lo posible, las empresas subastadas ("nacionalizadas", dado que los nuevos propietarios habían de ser españoles) tuvieran asegurada la asistencia técnica y comercial de las matrices alemanas, aunque quedaran en manos de sus antiguos directivos, algo posible siempre y cuando estuvieran fuera de las listas aliadas ${ }^{22}$. El departamento económico de Exteriores se las arregló muy bien, en el transcurso del bloqueo, para acortar la lista más sensible desde un punto de vista político, la que recogía los nombres de altos directivos de empresa miembros del Partido Nacionalsocialista (NSDAP) o sospechosos de haber colaborado con los servicios de espionaje alemán ${ }^{23}$. De esa lista salieron, entre otros, los ya citados Johannes Bernhardt, Fernando Birk, y Federico y José Lipperheide. Colaborar con los Aliados u obtener la nacionalidad española fueron las vías de escape más frecuentes.

¿Y los negociadores alemanes? Sólo empezaron a actuar en 1949, al recuperar la soberanía el país (ahora República Federal de Alemania). Su desorientación era enorme, pues carecían de una información mínima sobre los activos alemanes en España y el estado del proceso de expropiación ${ }^{24}$. Sus aspiraciones iniciales se fueron moderando a medida que iban chocando con la dureza de la CEBE y las exigencias económicas de los Aliados. Pero la representación diplomática se enfrentaba, sobre todo, a un problema legal de primer orden: a los herederos del III Reich les correspondía indemnizar a los propietarios alemanes. De ahí que el ministerio alemán de Exteriores acabara delegando en una sociedad creada ex profeso, Studiengesellschaft für privatrechtliche Auslandsinteressen E.V., la defensa de los intereses de las empresas expropiadas, mientras los diplomáticos centraban sus exigencias en torno a dos puntos: la recuperación de parte del patrimonio inmobiliario y la garantía por parte del Estado español de que los antiguos propietarios pudieran volver a comprar sus empresas. Para el Ministerio de Asuntos Exteriores alemán, la expropiación estaba íntimamente ligada al nacionalismo económico español que representaba la ley de 1939. Buena

\footnotetext{
21 Collado (2001).

22 Martín Aceña, con otros (2001), p. 208. Utilizamos el término "nacionalizar" para el traspaso de propiedad de manos extranjeras a "nacionales", esto es, españolas (tanto públicas, como privadas).

23 NARA, RG226/E19/B169/R12621.

24 Sobre las autoridades alemanas, AA, B62-237, B62-239, B62-276, B26-47, B51-245-00, B51-245-03, B51-245120, B51-245-148.
} 
parte de las empresas alemanas habían comenzado a ocultar su verdadera naturaleza desde entonces.

En el Cuadro 1 puede observarse lo decepcionante que la liquidación de los bienes industriales privados alemanes resultó finalmente para los responsables del programa Safehaven en España. De acuerdo con la lista publicada en el Boletín Oficial del Estado al término de la II Guerra Mundial (14 de abril de 1946), fueron bloqueadas 261 empresas, de las cuales muchas saldrían de la lista al demostrarse que, o bien no eran de propiedad alemana, o bien eran lo suficientemente antiguas como para no considerarse objeto de bloqueo ${ }^{25}$. De acuerdo con la estimación de los Aliados, el valor de mercado de los activos industriales y comerciales germanos ascendía a 700 millones de pesetas, de los cuales más del 90 por 100 correspondía a los cuatro sectores recogidos en el cuadro. Tras el trabajoso proceso de expropiación, sólo se obtuvieron 177 millones de pesetas, menos del 23 por 100 de lo previsto, de los que más de la mitad correspondían al sector químico y farmacéutico. $Y$ es que ni todas las empresas fueron finalmente expropiadas ni, sobre todo, se obtuvo el valor inicialmente estimado por los Aliados, entre otras cosas para minimizar la salida de unas escasas divisas ${ }^{26}$. Las bajas valoraciones por parte de los interventores españoles levantaron quejas entre las autoridades aliadas, especialmente cuando, a pesar del carácter reservado de este capítulo, se supo que, para contrarrestar los reducidos justiprecios, las empresas adjudicatarias debían destinar fondos a la investigación en España $^{27}$. Para los Aliados, no obstante, el resultado de la liquidación de los bienes alemanes en España fue mejor que el de los casos portugués y suizo (1,5 por 100 de la valoración inicial, en el primer caso, y un 11,2 ó 3,74 por 100, según las dos estimaciones realizadas, en el segundo, frente al 34,53 por 100 español), aunque peor que el sueco $(73,32 \text { por } 100)^{28}$. La depreciación de los activos alemanes con el transcurrir del tiempo, así como los intereses estratégicos de los Aliados - la reanudación del comercio internacional y el fortalecimiento de la defensa del bloque occidental一, facilitaron que Estados Unidos, Francia y el Reino Unido se conformaran con cantidades mucho menores que las inicialmente estipuladas.

\footnotetext{
25 AMAE, R7730 y R7737.

26 "Nota informativa respecto de un proyecto de propuesta de los Representantes Aliados para la liquidación del Convenio de 1948", 23/22/1954, AMAE, R4209/8. También CEBE, Actas 59 (27/05/49), 72 (21/07/49), 78 (21/09/49), 91 (12/11/49) y $92(14 / 11 / 49)$. AMAE, R7730. Una relación de las 75 empresas expropiadas y adjudicadas en Martín Aceña, con otros (2001), pp. 200-205.

27 Bien desarrollando laboratorios propios, destinando fondos al Consejo Superior de Investigaciones Científicas (CSIC), o, en el caso de la banca y las aseguradoras, a centros de formación y orfandades. La mayoría de estos compromisos perdió vigor en fechas tan tempranas como 1955. CEBE - Comisión Liquidadora, Acta 260 (14/12/1955), AMAE, R7731/2.

28 US Department of State (1998), Cuadro 2.
} 


\section{La pugna por los activos}

El Cuadro 1 nos va a servir de guía a lo largo de las páginas siguientes. En ellas analizaremos el proceso de expropiación de las empresas alemanas en España. No describiendo cada caso, sino identificando y explicando las estrategias adoptadas por las empresas intervenidas y por los grupos que acudieron a los concursos. Si las primeras representan la influencia extranjera en España, los segundos nos permiten evaluar la voluntad y la capacidad nacionalizadora del tejido empresarial español, además de su habilidad (y la de otras empresas extranjeras radicadas en el país) para identificar y aprovechar las oportunidades creadas por la expropiación. La información se ha organizado sectorialmente, tanto para que el lector no pierda la visión de conjunto como para ser fieles a la historia del proceso, que tuvo un tratamiento sectorial. Las dos columnas de la derecha dan una idea bastante cabal de cómo se desarrollaron los concursos: despertaron un interés desigual (dependiente del valor y de las expectativas que generaba) y la mayoría de ellos se resolvió a favor, en primer lugar, de los propietarios alemanes y de sus socios, tradicionales o no, españoles, y, en segundo, de los grupos nacionales que se habían asegurado la colaboración técnica o comercial germana.

La CEBE, y el Consejo de Ministros en última instancia, apostó claramente por asegurar la continuidad técnica de las industrias afectadas por el proceso, aún a costa de desechar propuestas realizadas por grupos, nacionales e internacionales, de peso. Eso sí, negoció hábilmente los justiprecios, en especial las cantidades destinadas a investigación (y de las que no se hacía partícipe a los Aliados), aunque ello obligara a convocar un segundo concurso ${ }^{29}$. Además, siempre se lograron mejoras sustanciales —como la ampliación de la asistencia a más productos y procesos o reducciones de los cánones- en los contratos establecidos con las casas matrices. Es cierto, no obstante, que en alguna ocasión fue reacia a mantener el control alemán. Así sucedió en AEG y Continental, dos concursos muy reñidos en los que participaban el INI e importantes grupos españoles y extranjeros, y donde la asistencia técnica, en definitiva, parecía asegurada.

Del desarrollo de los concursos, finalmente, dependería la relación entre los antiguos y nuevos propietarios. Aunque predominaría la colaboración, también surgirían conflictos. 


\subsection{Las estrategias de las empresas intervenidas}

Garantizar la continuidad de la asistencia técnica a las filiales fue la principal estrategia desarrollada por las empresas alemanas para mantener el control de sus propiedades en España. Con propuestas encabezadas por socios españoles (tanto históricos como sobrevenidos) cumplieron los deseos de la CEBE. En los casos en los que la matriz alemana, generalmente durante la II Guerra Mundial, optó por ampliar capital para reducir su visibilidad en la filial española, los socios instrumentales ganaron peso, no ya en el seno de la empresa, sino ante los interventores españoles. Pero el concurso dio pie a otras estrategias. Una consistiría en crear grupos ad hoc, a veces muy heterogéneos. Otra, en establecer alianzas con grupos extranjeros de países aliados.

La estrategia continuista fue la preferida por las empresas electrotécnicas. El grupo AEG prestaba colaboración técnica y comercial al finalmente adjudicatario de sus activos, Nueva Montaña, grupo de 27 compañías industriales muy diversas del norte de España que contaba con el respaldo de los bancos Central, Santander, Pastor e Hispano-Colonial. En el caso de Siemens, la firma alemana primero retuvo el control de sus filiales, Siemens Reiniger Veifa e Industria Latina de Electricidad Aplicada (ILDEA), a través de Cinerahl, empresa creada ad hoc por el grupo alemán en 1946 y encabezada por Hipólito González Parrado (Marqués de Llano) y José Luis Gallego (vinculado al grupo Urquijo). Un año más tarde, la cabeza de grupo se adjudicaba - por un justiprecio muy reducido a juicio de la propia $\mathrm{CEBE}$ - al único concursante, el grupo español (minoritario) presente en su consejo de administración: Francisco Aritio Gómez (luego presidente), Enrique Landa Somarriba (fideicomisario de Siemens Schuckert, consejero de ILDEA y Veifa), Jose María Aguirre Gonzalo, Antonio Lucio Villegas, Ignacio Muñoz Rojas y José María Oriol y Urquijo. Salvo los dos primeros, todos ellos se habían ido incorporado al consejo de la empresa después de $1935^{30}$.

La misma estrategia, combinada con una hábil presión sobre algunos oportunos contactos, fue aplicada por Osram. Así, a principios de 1948, más de un año antes de convocarse el primer concurso, Joaquín Chapaprieta y César de la Mora, los socios españoles de la firma alemana, junto con el representante designado por la embajada británica en su consejo de administración, comenzaron a presionar al ministro Alberto Martín Artajo para que intercediera a su favor en los futuros concursos ${ }^{31}$. Poco después les llegaba su primer logro: la adjudicación, con expresa recomenda-

AFSA (1935) y Cuadro 1.

Ya en julio de 1945, el Consejo Permanente del Consejo Económico Sindical pedía a los Ministerios de Asuntos Exteriores y de Industria y Comercio que los directores y trabajadores de las empresas expropiadas tuvieran preferencia en la compra de las acciones sujetas a inmovilización. Curiosamente, el secretario general de dicho organismo (que no firmante de la carta) era Martín Arrúe, vinculado a Osram y miembro del grupo adjudicatario. 
ción del interventor de la CEBE, y a pesar de la oposición aliada ${ }^{32}$, de Fabricación Nacional de Lámparas Eléctricas (FNLE). Con ello se pretendía no desgranar el grupo hasta que llegara el concurso de la matriz, procedimiento que curiosamente sólo se siguió aquí. No obstante, para cubrirse las espaldas, el grupo alemán también había presentado una segunda propuesta encabezada únicamente por los accionistas españoles - existía una tercera, presentada por un gerente de la filial (Gabriel Martínez López), que aseguraba presentarse a título particular sin que hayamos encontrado pruebas que señalen lo contrario- - El mismo razonamiento se siguió desde la Comisión para la adjudicación de la segunda filial, Manufacturas Ibéricas de Lámparas Eléctricas SA (MILESA), aunque su concurso fuera convocado tras el de Osram. El de MILESA fue un caso menos reñido. Pero sólo aparentemente: cuando se hizo público su anuncio, la Comisión ya debatía únicamente entre dos concursantes para la adjudicación de todo el grupo, los accionistas españoles de la entidad, encabezados por Chapaprieta, y Vidrios Belgor. El proceso se cerraría con la decisión del Consejo de Ministros de conceder los activos de Osram al primero. Además de presentar la "ventaja de continuidad", asegurada por el apoyo técnico de Osram y otras firmas extranjeras $^{33}$, la oferta de Chapaprieta contaba con el apoyo financiero de diversos bancos españoles (Central, Santander y Bilbao) y el beneplácito de los sindicatos. Pero éstas no eran las únicas razones: entre la fecha de su dictamen y la decisión ministerial, la Comisión estuvo negociando directamente las condiciones de la adjudicación con sus dos elegidos, especialmente con el grupo de Chapaprieta, quien llegó a comprometerse a nacionalizar el capital, ampliar los recursos destinados al CSIC e incluir un representante del Estado en el nuevo consejo de administración (hasta 1961).

Los contactos en la Administración también sirvieron a los "amigos del BAT", el grupo de consejeros, apoderados y directivos del Banco Alemán Transatlántico (BAT) - entre los que se encontraban Federico Marimón y Josep Pellicer-, que se hizo con sus activos ${ }^{34}$. A juicio del americano Herman Kasper, la voz más dura del CCA, detrás de la oferta se encontraba también Blas Huete, antiguo director de la

32 CEBE, Acta 117 (23/2/1950), AMAE, R7730.

33 Osa, Sociedad de Estudios para el Alumbrado, Westinghouse y Lumalampan. Todas ofrecían, además, los materiales precisos para la fabricación de lámparas especiales y tubos fluorescentes, productos hasta entonces importados. La asistencia técnica de las dos primeras se remontaba a la creación de Osram. La suiza Osa, en concreto, había gestionado hasta la II Guerra Mundial las patentes del cártel Osram-Philips-Cie. de Lampes. Controlada por Siemens, International General Electric poseía un interés minoritario. AMAE, R9941/7; y CEBE, acta 51 (30/03/49), AMAE, R7730. Por otro lado, la propuesta de los accionistas españoles mantenía las redes comerciales tradicionales de Osram, apoyadas en Siemens, AEG y Zenker.

34 En el consejo de administración del BAT figurarán: J. Pellicer y D. Carceller (hombre de Cepsa y temporal ministro de Industria) como presidente y vicepresidente; I. Coll (de Damm y otras), C. Fabra, A. García Munté (Plus Ultra), J. López de Ayala, O. Maier, F. Marimón (representante de los alemanes en varias empresas), J. Mas-Sardá, J. Torra, A. Sala Amat y A. González Fierro. AFSA (1950/51). 
sucursal española y, por aquel entonces, responsable del Instituto Español de Moneda Extranjera (IEME) y miembro de la $\mathrm{CEBE}^{35}$. Ello permitió que las quejas aliadas cayeran en saco roto, a pesar de que el CCA contaba con pruebas fehacientes -una carta interceptada por las autoridades francesas- de que todo había sido una maniobra dirigida por el grupo alemán. La defensa del status quo bancario, la naturaleza mesocrática del grupo y la parte de los dividendos que ofrecían destinar a fines educativos y científicos bajo los auspicios del Consejo Superior Bancario, apoyaron su defensa por parte de la Comisión.

La química también nos ofrece algunos ejemplos de esta estrategia. Los concursos de AGFA, Abelló Oxígeno Linde y Unicolor, además de concurridos, fueron resueltos a favor de los antiguos propietarios. En el caso de AGFA, la empresa pasó al antiguo gerente de la firma, Enrique Herold, amparado por los socios catalanes ${ }^{36}$; en el de Abelló, a la familia del mismo nombre. Unicolor, una pieza clave en el entramado químico hispano-alemán, fue a parar a manos del Banco Comercial Transatlántico, el antiguo Banco Alemán Transatlántico, y del propio Birk.

En algunas ocasiones, como ya se ha apuntado, la organización de propuestas nacionales para los concursos fue precedida de ampliaciones de capital conducentes a reducir la participación alemana. Así sucedió en los casos de Telefunken, Plus Ultra y Continental. Del tercero hablaremos más adelante. En el primero, pieza clave en la red de espionaje nazi en España, cuando el CCA logró tener acceso a su documentación, sólo un 25 por 100 de la propiedad estaba en manos de la matriz alemana. El testaferro más relevante era su consejero delegado, Waldemar Herold, que en 1940 consiguió la nacionalidad española. Los Aliados interrogaron a Herold, protegido por Exteriores. Su muerte en 1950 hizo que al concurso se presentara sólo uno de los testaferros españoles, Antonio Barroso, que se haría con los activos alemanes sin problemas. En Plus Ultra, Allianz Versicherungs $A G^{37}$ redujo su participación en el capital a la mitad (del 98 al 48,16 por 100) ya en 1944, con el apoyo gubernamental español y para desesperación de los Aliados. Sería un caso conflictivo, tanto por la falta de entendimiento entre la CEBE y los Aliados como por los concursantes. Uno era Cervantes, respaldado por el grupo Fierro. Y otro era la propia Allianz, represen-

NARA, RG 59/Decimal File (DF)1950-54/R652.62. Tras la adjudicación, Huete tuvo que dejar su cargo en el IEME y comprometerse a no ocupar ningún puesto directivo en el BCT. Huete había defendido en la CEBE la nacionalización (y no disolución) de la banca alemana. Martín Aceña, con otros (2001), p. 209.

36 Caso que muestra muy bien la confusión y picaresca que generó el proceso de expropiación. Collado (2001), pp. 332-341.

37 La participación mayoritaria de Allianz databa de 1926 (Feldman, 2001). Según el CCA, también tenían una participación, desde 1942-1943, la Münchener Rückversicherungs Gesellschaft y Magdeburguer Rückversicherung. Ambas la reclamaron en 1950, al quedar fuera del bloqueo. Frax y Matilla (1998), p. 15. Según la CEBE, sin embargo, Allianz poseía el 100 por 100. CEBE, acta 186 (8/2/50), AMAE, R 7731. 
tada por Antonio Satrústegui, presidente desde 1943 de la aseguradora, y Antonio Garrigues Díaz de Cañabate, colaborador de los Aliados durante el bloqueo. Las gestiones de Fierro, no obstante, provocaron el retraso suficiente como para que este expediente se declarara en suspenso en agosto de 1952, después de que la Comisión hubiera resuelto la adjudicación a favor del grupo Satrústegui ${ }^{38}$.

Una segunda estrategia desarrollada por los intervenidos consistió en crear empresas ad hoc encabezadas por españoles de confianza. Ejemplos de esto fueron Cinerahl, de la que ya hemos hablado; Vesta, fundada en 1946 por la Victoria de Berlín cuando la última ya estaba intervenida; y J. Pujadas, sociedad barcelonesa fundada por Federico Marimón para hacerse con los activos de Boehringer, una de las empresas en las que actuaba como testaferro ${ }^{39}$. Nordstern, por su parte, aprovechó con el mismo fin Meridional, la subsidiaria española que se había creado en 1942 para evadir el nacionalismo franquista ${ }^{40}$.

Por último, algunos grupos optaron por presentarse a los concursos asociados a grupos extranjeros no alemanes. Fue el caso de AEG, que brindaba apoyo comercial a Andiesa, junto al Banco Exterior y la filial británica de International General Electric (IGE), socia histórica de la multinacional germana ${ }^{41}$. Y fue también el caso de Continental, que se presentó al concurso por medio de la multinacional norteamericana General Tire \& Rubber y del empresario español José Luis de Aznar. Contaba, además, con el apoyo de Antonio Aguirre Gonzalo, encargado de defender su opción frente a otros candidatos: el INI, Feliu y el Banco Central. Estos dos últimos eran socios fundacionales de Continental en España. Alentado por la embajada británica, Feliu denunció repetida y estérilmente irregularidades de la gestión alemana durante la II Guerra Mundial ${ }^{42}$.

El tiempo, ciertamente, corrió en contra de los Aliados y a favor de los antiguos propietarios y sus socios españoles o naturalizados. La farmacéutica Merck constituye un caso extremo, a la vez que único en el proceso que estamos examinando. Por dos razones aparentes: los Aliados se hicieron con toda la documentación (que probaba que Merck era totalmente alemana) y había sospechas de que su consejero-delegado, Andress Moser, había coordinado la red de espionaje nazi de Barcelona. La expropiación de este laboratorio se convirtió así en un pulso entre el CCA, que diri-

38 La causa del desencuentro entre los dos concursantes era, al parecer, el hecho de que el grupo de Satrústegui mejorara su oferta a posteriori. AMAE R4301/6.

39 AMAE R9942/4 y NARA RG226/E19/B254/RXL16424.

40 En su consejo se encontraba Marimón Grifell. Un porcentaje minoritario de la sociedad pertenecía a Nacional de Reaseguros, también vinculada (a través de la familia Sunyer) con Vesta. AFSA (1950/51). Agradecemos a Elena Eugercios (ERGO Generales Seguros y Reaseguros SA) la información sobre Meridional y Victoria de Berlín.

41 En España ambas, junto con la francesa Thomson-Houston, habían fundado General Electric Española (Geathom) en 1931.

42 La adquisición por parte de la filial comercial (española) de la mayoría de las acciones de la filial industrial (alemana) y un contrato de cesión de titularidad del capital firmado en 1941. AMAE, R4318/12. 
gió los trabajos de la CEBE, y el resto de la Administración española, movilizada por la matriz alemana. Con tanta eficacia que la propia Presidencia de Gobierno dejó en suspenso (definitivamente) la adjudicación, decidida por la Comisión a favor del único postulante, el grupo Urquijo ${ }^{43}$. Algunas aseguradoras corrieron la misma suerte, pero por una razón más simple: su situación financiera crítica, que llevó a algunas a quebrar durante el proceso y a la propia CEBE a convocar segundos concursos, buscar candidatos o rebajar de forma sustancial el justiprecio ${ }^{44}$.

\subsection{Las estrategias de los concursantes}

Los concursos también provocaron una movilización importante en el tejido empresarial español. De su análisis se deduce que hubo tres estrategias predominantes: las iniciativas españolas con colaboración técnica y comercial alemana; las alianzas con otros grupos extranjeros; y las propuestas, privadas y públicas, de corte autárquico. También, que hubo un gran vencedor, el grupo Urquijo.

En el sector químico imperó la primera estrategia. La razón última era la voluntad de diversos grupos españoles de desarrollar sus propios complejos industriales sobre la base técnica y comercial germana. El más ambicioso, con diferencia, fue el Urquijo, que acudió al concurso con un plan (crear un complejo químico y farmacéutico nacional con asistencia internacional) y dos empresas, Productos Químicos Sintéticos SA (Proquisa) y el Consorcio Químico Español, constituidas en 1944 y 1948. Ambas sociedades reflejan la capacidad de movilizar recursos, buscar alianzas, presionar a los poderes públicos y ejecutar proyectos de este grupo industrial. El Urquijo logró agrupar, en efecto, al grueso de la química española (la Unión Española de Explosivos, UEE, y Cros) con el fin de hacerse con la mayoría de las empresas químicas alemanas. No lo logró completamente, es cierto. Como puede observarse en el Cuadro 1, Cros optó en solitario (y con el apoyo de su socia histórica Hoechst) a la Sociedad Electro-Química de Flix. Por su parte, FNCE se negó en redondo a formar parte del consorcio y luchó sola por la plena propiedad de su empresa, participada por IG Farben desde 1926. Del concurso se ocuparon, sobre todo, Pellicer y Milà, que además de contar con la ayuda de Antonio Robert, entonces director general de Industria (y más tarde consejero delegado de Proquisa), pudieron, por medio de Birk y del director técnico de FNCE, Karl Raeck, llegar a un acuerdo global con el director de Bayer ${ }^{45}$. La estrategia, no obstante, no resultó con Unicolor.

43 NARA, RG226/E19/B304/RXL21423 y Cuadro 1.

44 Ello permitió en otros casos que las matrices alemanas se hicieran fácilmente con sus filiales en los concursos. Frax y Matilla (1998) y Cuadro 1.

45 BAL 9/L y 302/211 “FNCE Probleme”. 
Los grandes triunfos del Urquijo fueron los grupos Bayer y Schering. Desde 1939, ambas habían entrado en la órbita del Urquijo con la intermediación de personas como José Luis Gallego (director de propaganda científica de La Química Comercial y Farmacéutica entre 1936 y 1943), el conde Seefried (austríaco procedente de la división internacional de Schering $A G$, donde había actuado como puente entre los socios españoles y alemanes ${ }^{46}$ ) o el ubicuo Adolfo Domínguez, entre otros muchos ${ }^{47}$. La presencia activa de estos individuos en las filiales de Bayer y Schering puso al Urquijo en una situación inmejorable para llegar a acuerdos con las matrices de Leverkusen y Berlín y para diseñar planes del agrado de la CEBE. En el caso de Merck, al que ya se ha hecho referencia, la excelente maquinaria del Urquijo chocó con la resistencia a colaborar de la matriz alemana.

Pero no sólo el Urquijo fue ambicioso. Las relaciones de Federico Lipperheide con la IG y el Partido Nazi fueron el argumento empleado por los Aliados para vetar su participación en el concurso y en la movilización de la industria química españo$1 \mathrm{a}^{48}$. Lipperheide, sin embargo, no se arredró. Primero intentó, sin éxito, hacerse con La Química, a través de General Química y contando con la asistencia técnica de Bayer. Y luego logró firmar una serie de acuerdos con Bayer y con otras firmas químicas y farmacéuticas alemanas, gracias a los cuales construyó uno de los dos grandes grupos químicos de la España autárquica.

La banca también nos ofrece un ejemplo de iniciativa nacional con colaboración alemana. La Banca de Medina, una institución modesta fundada en 1892, se hizo con el concurso del Banco Germánico del Sur prometiendo continuar con su labor a partir de la colaboración (documentada) de sus directivos y socios. Todo ello tras una ampliación, autorizada, para que la familia Fernández de Araoz (promotora, a su vez, del BAT) ampliara su participación en la compañía.

Algunos de los competidores más directos de las firmas alemanas formaron parte, a través de sus socios en España, del proceso de bloqueo, si bien no hemos podido averiguar siempre de quién provino la iniciativa. En el concurso de Abelló, por ejemplo, se mostraron muy interesados la Sociedad Española de Carburos Metálicos, creada con capital suizo en 1897 y a la que Abelló había estado prestando asistencia técnica, y la Sociedad Española del Oxígeno, filial de la francesa L'Air Liquide (socia de Linde en diversos mercados hasta la guerra $)^{49}$. Similar fue el caso de Firestone, que participaba en el concurso de Continental al lado del grupo Hispano-Urquijo, además de apoyar la oferta de Galindo, una firma catalana con la que Continental tenía un

$46 \quad$ Kobrak (2002), pp. 321-321.

47 De esta realidad, extensible a La Minera/Fodina, tuvieron constancia tanto los Aliados como los interventores españoles. Los primeros fueron quienes generalmente suministraron la información a los interventores. NARA, RG226/E19/B314/R22808 y RG226/E19/B2/F8/R158381.

48 NARA, RG226/E19/B3/F16/R165726.

49 Dienel (2004), pp. 79-80. 
acuerdo de asistencia técnica. Otros ejemplos son los de Babcock \& Wilcox (Vickers) en AEG; Hoechst en La Química Comercial y Farmacéutica a través de Activión; y Philips y Compagnie de Lampes (cofundadoras de FNLE y MILESA) en Osram en el grupo encabezado por los españoles Alberto Aguilar Gómez-Acebo y Tomás de Bordegaray, y asistido por International General Electric y Thomson-Houston. Menos claro fue el caso del Chemical Bank, en cuyo nombre acudió al concurso del Banco Germánico del Sur Jaime Suriñac, sin que terminara de esclarecerse nunca su relación con el banco americano. A pesar de ofrecer la asistencia técnica de empresas de reconocido prestigio, ninguna de estas ofertas salió adelante.

El grupo Urquijo alentó algunos proyectos amparándose en la asistencia de firmas extranjeras no alemanas. Además del proyecto de Firestone, el Cuadro 1 muestra su participación en el consorcio encabezado por La Maquinista Terrestre y Marítima - y apoyado por Brown Boveri y Oerlikon - que optaba a AEG; y en el concurso de La Minera/Fodina como único candidato a través de Explotaciones Potásicas. Fue éste un caso controvertido y con proyección internacional. El complejo minero formaba parte del cártel franco-alemán. Según la información llegada a la CEBE, el Urquijo había actuado desde el final de la guerra de acuerdo con la embajada británica en Madrid, dispuesta a evitar a toda costa que el mercado mundial de las potasas quedara en manos francesas. De ahí que la creación en 1945 de Explotaciones Potásicas y la estrategia del Urquijo (que no tardó en vender la empresa a sus socios de UEE) se calificaran de maniobra británica ${ }^{50}$. El asunto se zanjaría más tarde adjudicando Fodina al INI y La Minera a la empresa del Urquijo.

El nacionalismo económico oficial probablemente dio alas a las propuestas con una orientación más autárquica presentadas en los concursos, encabezadas por ingenieros que pretendían desarrollar una auténtica industria nacional con personal y materiales del país, bien creando nuevas empresas o, generalmente, aprovechando otras ya existentes. A este objetivo respondían las propuestas de Electroválvula (creada en 1946 a propósito de concurso de Osram), Vidrios Belgor (Osram), Manufacturas Médicas (filiales de Siemens), Vicente Ferrer (La Química Comercial y Farmacéutica) y Feliu (Continental). Algunos grupos financieros, como Fierro (Continental), los grupos Santander y Madrid (AGFA) y el Banco Central (Continental), explotaron su poder de mercado con el mismo fin y sin éxito.

Los servicios proporcionan variados ejemplos de lo mismo. En el sector asegurador hubo dos casos en los cuales los accionistas españoles aprovecharon la coyuntura del final de la guerra y la intervención aliada para aprobar ampliaciones de

50 Según el informe de la asesoría jurídica del Ministerio de Asuntos Exteriores del 1 de junio de 1946. MAE R4312/3. Ambas empresas eran propiedad en un 75 por 100 del Sindicato Alemán de Potasas y controladas plenamente por el mismo a pesar de que el 25 por 100 de Fodina estuviera en manos francesas. 
capital con el fin de aumentar su control al margen de las matrices alemanas. Así parece que sucedió, por su trayectoria posterior, en La Constancia ${ }^{51}$ y la Compañía Europea de Seguros de Mercancías y Equipajes (Compañía Europea de Seguros de Equipajes desde 1944). En el caso de la Compañía Europea, además, la familia Delás, su principal accionista español y testaferro de algunas de las acciones alemanas, era la fundadora del otro concursante, La Catalana de Seguros de Prima Fija y su filial La Previsión Nacional $^{52}$. Anteriormente, los Delás habían intentado hacerse con la aseguradora germana a través del Banco Vitalicio ${ }^{53}$. Otros concursantes nacionales corrieron menos suerte, al quedarse en suspenso los expedientes por los que luchaban. Así les ocurrió a Finisterre (en el concurso de Mannheimer), Cervantes (Plus Ultra) y Hermes, Financiera Nacional de Seguros y Reaseguros, Orión y Los Previsores del Porvenir (la Victoria de Berlin $)^{54}$.

En el sector financiero, los competidores eran especialmente poderosos en el caso del BAT. El llamado "grupo promotor del Banco Internacional Transatlántico" estaba integrado por José Entrecanales, Pedro Gual, Felipe Rodés, Alfonso de Hoyos (duque de Almodóvar del Río), Joaquín Chapaprieta (hombre de Osram en España), Alejandro Fernández de Araoz, Pedro González-Bueno y José Solchaga. Sin renunciar a las relaciones comerciales con Alemania, los promotores se proponían dar una dimensión internacional más amplia al banco, creando vínculos con los otros grandes socios comerciales de España y fortaleciendo su vocación industrial. En la memoria redactada al efecto, el grupo destacaba sus numerosas conexiones con grandes empresas españolas y extranjeras. La segunda oferta venía respaldada por los bancos Español de Crédito y Central, el "grupo bancario" según la CEBE, cuyo objetivo era liquidar el BAT. El concurso del Banco Germánico de la América del Sur reunió propuestas variopintas. A la de Jaime Suriñac anteriormente mencionada, se unieron las del fabricante de whisky DYC, Nicomedes García, que pretendía aprovechar la red del banco alemán para reforzar su presencia en el mercado internacional de licores; y la del Banco Popular Español, que a través de la Mutualidad de Seguros Generales Los Previsores del Provenir, quería incorporar los activos alemanes a su cartera.

51 Estrategia apoyada por el Director General de Seguros y encabezada por Víctor Ríu (también detrás de Carburos Metálicos en el concurso de Abelló) ante la crítica situación financiera de la sociedad. El nuevo Consejo también contaba con el omnipresente Marimón Grifell. La trayectoria posterior de la entidad nos induce a descartar que la ampliación fuera una maniobra alemana para eludir el bloqueo, como han apuntado Frax y Matilla. Frax y Matilla (1998), p. 14.

52 Pons (2002).

53 Y a un precio (800 pesetas) muy inferior al justiprecio final. Desde 1948, la CEBE había estado negociando su adjudicación, también con la Compañía Hispano-Americana de Seguros y Reaseguros. AMAE, R10000/8.

54 Por volumen de activos, en 1950 eran de las más significativas. AFSA (1950/51). En el caso de Plus Ultra, es llamativo que sus competidoras más directas en el ramo de transportes — La Unión y El Fénix, el Banco Vitalicio, Bilbao y Assicurazioni Generale (Pons, 2002, p. 96) - no intentaran hacerse con su cartera de clientes. 
En general, la búsqueda de apoyos en la Administración fue poco efectiva para los concursantes nacionales. Como mucho, lograron retrasar las adjudicaciones. Los casos de Orión, Vidrios Belgor y Electroválvula, muy bien documentados, dan idea de ello. La primera optaba a los activos de la Victoria de Berlín y contaba con contactos como los ministros Alberto Martín Artajo y José María Fernández Ladreda. Se consiguió suspender el primer concurso apelando a presuntas irregularidades, sobornos y afiliaciones ideológicas poco "patrióticas" del resto de los concursantes. En el caso de Vidrios Belgor, el apoyo directo de Demetrio Carceller explica probablemente que la CEBE adjuntara su propuesta a la de los adjudicatarios finales ante el Consejo de Ministros, pero eso fue todo. Y en el caso de Electroválvula, finalmente, las apelaciones avaladas por Martín Artajo y Mariano Iturralde resultaron también estériles.

El instrumento más importante del nacionalismo industrial oficial, el INI, tuvo un escaso protagonismo en todo el proceso. Es cierto que, por diversas razones, Navasqüés renunció al proyecto inicial de traspasar todos los activos germanos al Instituto $^{55}$. De hecho, el INI sólo se presentó en dos concursos (AEG y Continental), sin que ninguno se resolviera a su favor. En otro caso, el de Siemens, la CEBE intentó, con poco éxito, que se presentara el Instituto para incrementar el número de ofertas y así mejorar la oferta del único concursante ${ }^{56}$. En Fodina, fue un recurso de última hora. Suanzes, por otro lado, opinaba que las adjudicaciones que interesaran al organismo que presidía debían hacerse directamente, sin mediación de concurso alguno, algo a lo que nunca se accedió desde la Comisión ${ }^{57}$.

\section{La recuperación de la propiedad y del control}

En el Cuadro 2 hemos resumido el proceso de recompra de los activos más importantes de la industria alemana en España. Muestra, para empezar, que a mediados de los años setenta, las veinte empresas más importantes volvían a estar controladas ampliamente por sus antiguos propietarios. También pone de manifiesto que, a pesar del tiempo transcurrido desde el final de la guerra mundial, en los consejos de administración figuraban algunos individuos o familias destacados durante el bloqueo. No fueron raros los casos de funcionarios que aceptaron cargos más o menos

55 Para evitar paralelismos con el entramado empresarial nazi y garantizar la continuidad de la tecnología alemana en España. Martín Aceña, con otros (2001), p. 155.

AMAE, R4209/8.

57 Es ilustrativa la carta de uno de los interventores, Alejandro Suárez, a Iturralde en agosto de 1949, a propósito del concurso de la minera Stolberg Zinc, donde Adaro se hizo con los activos en un segundo concurso en el que el INI accedió a presentarse a instancias de la CEBE. AMAE, R4209/8; CEBE, actas 97 (18/11/49), 98 (19/11/49), 101 (5/12/49), 105 (21/12/49), $134(11 / 5 / 50)$ y 137 (23/5/50). AMAE, R7730. 
consultivos en esas empresas o en las de sus socios españoles. El ejemplo más significativo es el de Navasqüiés, consejero de Cros en las fechas que nos ocupan. No todos los actores cuya pista hemos tratado de seguir sentían el mismo agradecimiento por el maestro de ceremonias del bloqueo. Los negociadores de la joven República Federal de Alemania, por ejemplo, no respiraron hasta que Navasqüés fue sustituido por García de los Salmones, y éste allanó el camino que llevaría al acuerdo diplomático de 1958. Pero en los círculos empresariales hispano-alemanes se le miraba con simpatía. Que el ex diplomático español fuera consejero precisamente de Cros, además, nos ayuda a entender lo compleja que fue la relación entre el nacionalismo económico oficial y la asistencia polifacética de las empresas extranjeras. En la columna de la derecha puede comprobarse cuál fue el papel desempeñado por las empresas o los consorcios adjudicatarios de los concursos. Las relaciones entre antiguos y nuevos propietarios fueron en general buenas y sirvieron para mantener la actividad de las antiguas filiales en nuestro país, tanto si la empresa quedaba en manos de viejos socios como si pasaba a ser gestionada por testaferros o por grupos creados expresamente para el concurso.

Pero hubo excepciones a esta regla. Las más notorias en la química, protagonizadas por dos viejos conocidos de la IG Farben: Cros y FNCE. La relación entre la primera empresa química española y la sociedad alemana fue espinosa por tres razones: el control de Flix (Hoechst temía una absorción por parte de Cros); su futuro (mientras Cros pretendía que Flix, además de producir cloro, fuera una plataforma para fabricar monómeros, Hoechst optó por la creación, con Shell y Explosivos, de Industrias Químicas Asociadas en 1961); y las relaciones de Hoechst con empresas de la competencia (como Energía e Industrias Aragonesas y Explosivos, ambas en la órbita del Urquijo, el INI, o la norteamericana Monsanto $)^{58}$. Los desencuentros se zanjaron en 1970, vendiendo Hoechst su participación en Flix (37,5 por 100) a Cros. Los problemas de FNCE arrancaban de la división del trabajo establecida por la IG Farben y otros socios internacionales de la gran química española a partir de 1926. Esto había marginado a la empresa catalana de campos nuevos y prometedores, a la vez que la ligaba a suministradores como Cros y, claro está, Unicolor, la plataforma comercial de las fundadoras y herederas de la IG Farben (Bayer, Basf y Hoechst) ${ }^{59}$. Pero, además, la empresa fue perdiendo competitividad y cuota de mercado al concluir la autarquía, y la presencia de las familias fundadoras en la dirección resultaba incómoda para los alemanes. Por ello el desembarco de Bayer en España se hizo con otros socios: la familia Cantarell (propietaria de Productos Electroliticos) en Cataluña y el grupo Urquijo (Proquisa) en Asturias. La agonía de FNCE se prolongaría hasta 1993.

\footnotetext{
58 Firmenarchiv der Hoechst (FAH) 67845 2/90/3, 29/4/61.

59 Las tres ampliarían, además, sus negocios en España por separado. Puig (2003).
} 
En lo que atañe a las demás filiales de los sectores químico y farmacéutico, los alemanes pudieron recuperar sin dificultades el control y la propiedad, recurriendo siempre a las ampliaciones de capital y remunerando con generosidad a los socios españoles (muchos de los cuales se jubilarían como directores y consejeros). La expansión del mercado español, el "milagro alemán" y el plan liberalizador del gobierno lo hacían rentable. Así, la recompra de La Química Comercial y Farmacéutica (desde 1968, Bayer Hispania Comercial) tuvo lugar entre 1960 y 1981; la de Schering, entre 1970 y $1980^{60}$; la de Boehringer Mannheim, en los sesenta; la de Abelló, algo más lenta por tratarse de una sociedad mixta, se prolongaría hasta los ochenta; y la de Merck (Igoda desde 1949) no fue necesaria por la paralización del concurso, aunque hubo un recambio importante de directivos. No es ocioso recordar que fue precisamente en los setenta cuando el Urquijo decidió (en una operación financieramente brillante) liquidar sus negocios químicos, que pasaron a manos de Explosivos, Cros y varios socios internacionales, como Bayer. Aunque es el caso peor documentado, Continental pareció resolverse del mismo modo y dentro de la estrategia general del grupo en Europa. Así, tanto Aznar como la americana General Tire velaron por los intereses de la matriz alemana, que en el curso de los sesenta logró hacerse con el 86 por 100 del capital de la filial española.

En el sector electrotécnico imperó la colaboración. Y es que, tal como las memorias presentadas al concurso dejaron entrever en su día, los adjudicatarios españoles, a diferencia de lo que ocurrió en los sectores químico y farmacéutico, carecían de ambiciones industriales y científico-técnicas. Las cuatro grandes empresas electrotécnicas siguieron funcionando de acuerdo con las directrices de la matriz, unas con mejores resultados económicos que otras, pero todas velando por la continuidad del negocio, la reputación de las marcas y la cuota de mercado. En el caso de AEG, Herbert Hellmann, director general desde 1934, se mantuvo en su dirección o en el consejo $^{61}$; mientras que Siemens, Telefunken y Osram funcionaron bien bajo la dirección de los adjudicatarios españoles, singularmente las familias Aritio, Aguirre, MuñozRojas y Botín. Otras personas significativas que encarnaron la continuidad fueron Martín Gamero, secretario del consejo de Siemens entre 1929 y 1972; Pedro González Bueno y Martín Arrúe Astiazarán, miembros del consejo de Osram antes del bloqueo $y$, respectivamente, presidente en los setenta y director general en los sesenta; y Enrique Landa Somarriba, director técnico y testaferro de Siemens que, si bien menos duradero, resultó esencial en la época de naturalización forzosa y bloqueo tanto en Siemens como en Osram. La recompra también se produjo vía ampliación de capital

\footnotetext{
60 Bayer y Schering dieron soporte, además, a dos proyectos del grupo Urquijo, la Compañía Española de Penicilina y Antibióticos (CEPA), asistida por la firma norteamericana Merck Sharp \& Dohme, y el Instituto Farmacológico Español (IFE). El IFE, de hecho, se concibió como una alternativa a los pagos destinados habitualmente al CSIC. Puig (2003). 
y de forma relativamente precoz (a finales de los cincuenta y principios de los sesenta) y amistosa ${ }^{62}$. La división electromédica de Siemens (Cinerahl), por la que asimismo habían velado personas clave del grupo farmaquímico del Urquijo, como José Luis Gallego e Hipólito González Parrado, acabó absorbiéndose en los sesenta.

Dada la regulación del sistema bancario español, la recuperación de la propiedad de la banca germana fue más laboriosa. Todo apunta a que los amigos del Banco Alemán Transatlántico se comportaron como tales, y que el banco, ahora Banco Comercial Transatlántico, siguió vertebrando la inversión directa alemana en España de acuerdo con las directrices del Deutsche Bank. Las familias fundadoras del Banco de Terrassa se mantuvieron en el consejo hasta los setenta, y la entidad alemana desplegó toda su diplomacia para aumentar su presencia en el BCT a medida que se ampliaba el capital. En 1957 consiguió hacerse con el 10 por 100 (y colocar a Hermann Abs en el consejo) y en 1971, con el 25 por 100. La operación no se completaría hasta el ingreso de España en la futura Unión Europea. Para entonces el Deutsche Bank contaba ya con dos filiales propias en Madrid (1973) y Barcelona (1981) ${ }^{63}$. La evolución del Banco Germánico de América del Sur, devenido Banco Internacional de Comercio a principios de los cincuenta, es más oscura. Aparentemente, los adjudicatarios no tardaron en asociarse al grupo de promotores que habían perdido el concurso del BAT, entre los que se encontraba el Urquijo. De este modo,se desvelaba el enigma que tanto había intrigado a los Aliados (o más bien a su representante más crítico, el americano Kasper): el Banco de Medina no era sino un instrumento de la gran banca española para hacerse con la segunda pieza de la banca alemana después de haberle sido denegada la primera. A mediados de los setenta, las familias Fernández de Araoz y Urquijo dominaban el consejo de la antigua filial del Dresdner Bank en España. A la espera de que vea la luz la historia oficial de esta entidad, no sabemos si la entidad alemana volvió a España absorbiendo este banco, creando su propia red de filiales o haciendo las dos cosas a la vez ${ }^{64}$.

En lo que concierne a las aseguradoras, La Constancia y la Compañía Europea de Seguros de Mercancías (más tarde Europea, Seguros de Viaje) quedaron en manos de los adjudicatarios españoles - Allianz y Münchener se establecieron de forma independiente en España en 1974 y 1954, respectivamente - ${ }^{65}$. Sí se mantuvieron los lazos en el caso de Plus Ultra. Aunque su expediente fue sobreseído, el grupo que se había presentado al concurso permaneció en la empresa hasta ser absorbida ésta por el Banco de Vizcaya en 1972 (actualmente forma parte del grupo francés Groupama).

\footnotetext{
62 Fondo del Banco Urquijo (FBU), Memorias de Siemens SA, 1960-1973.

63 http://group.deutsche-bank.es.

64 http://www.dresdner-bank.com.

65 Agradecemos a Miguel Martínez (Münchener) la información proporcionada.
} 
Por último, Victoria de Berlín siguió operando como Vesta hasta 1967, cuando recuperó el nombre original. Tres años más tarde, se fusionaba con Meridional, constituyendo Victoria-Meridional ${ }^{66}$.

\section{Conclusiones}

Para los principales actores implicados en la historia que se acaba de contar, la expropiación de las empresas alemanas se reveló como una misión de difícil cumplimiento. Por una razón: la desactivación del potencial económico alemán en España que los Aliados querían llevar a cabo en el marco del programa Safehaven, implicaba una desactivación del potencial económico español que casi nadie deseaba. El capital y la tecnología germanos eran vitales en sectores tan importantes como la química, la farmacia y la electrotecnia. Esto explica los pobres resultados económicos del proceso; el triunfo de empleados, socios y testaferros de los alemanes frente a alternativas nacionales en los concursos individuales; y la fácil recuperación de los activos por parte de las matrices alemanas después de 1958.

De los límites que la realidad económica y empresarial del país imponía al nacionalismo económico y a la politización de la economía fue consciente, en primer lugar, el organismo encargado de gestionar la expropiación, la CEBE, dirigida con eficacia por Navasqüés hasta 1957. Mayor conocimiento de causa tenían, en segundo lugar, los afectados directos de la expropiación, aunque la suma de nacionalismo, guerra, derrota y ocupación hubieran añadido incertidumbre al proceso que se desarrollaba en España. En la investigación hemos identificado tres estrategias dominantes, siendo la continuista la más extendida. La mayor parte de las alianzas que la sustentaría se forjaron entre 1944 y 1948, si bien los grupos españoles habían ido cobrando un creciente protagonismo con las primeras restricciones franquistas a la inversión extranjera. Y es que, tal como las autoridades de la República Federal de Alemania irían descubriendo con amargura, la mayoría de las empresas afectadas por el bloqueo se apresuró a buscar soluciones más o menos imaginativas que le permitieran continuar trabajando en España.

De las memorias presentadas al concurso y de la evolución real de sus empresas hasta mediados de los setenta deducimos que también los socios españoles, en tercer lugar, conocían los límites de esta oportunidad que la historia les estaba brindando. Los únicos casos en que la expropiación fue instrumental para crear empresas nuevas y ambiciosas se dieron en la química. Además de acabar en sonoros (aun-

66 ERGO Generales Seguros y Reaseguros SA desde 2005. Del grupo alemán ERGO también forma parte la antigua propietaria de La Constancia, Mannheimer (Hamburg-Mannheimer actualmente). Aunque en los cincuenta retomó sus actividades, ya no opera en España. Su rastro se pierde a finales de los ochenta. 
que rentables) fracasos, su función fue más financiera y comercial que técnica. Por más que casi todas las adjudicaciones se cerraran con un pago por este concepto al recién creado CSIC, la documentación que hemos manejado revela que nadie creía contribuir de este modo a superar el atraso técnico y científico español. En nuestro estudio identificamos tres estrategias distintas, que dieron lugar a empresas adjudicatarias constituidas por socios tradicionales, testaferros o grupos creados ad hoc, y a relaciones de colaboración o de conflicto. La primera fue bastante más frecuente que la segunda. Aunque todos los adjudicatarios ganaron (medida la ganancia en términos de rentabilidad financiera y de precio de venta de las acciones al autorizarse la inversión directa extranjera), hubo un gran ganador: el grupo Urquijo. Este importante actor de la industrialización española logró hacerse con la propiedad directa de una tercera parte del sector químico y farmacéutico, el control directo o indirecto del sector electrotécnico y la propiedad compartida del segundo banco alemán en España.

En el texto se ha señalado que muchos concursos fueron reñidos, abundando las presiones, la compra de favores, las intrigas y las denuncias. Aunque aquí no nos hayamos detenido en los perdedores, debe observarse que en algunas ocasiones los rivales llegaron a acuerdos posteriores al concurso y que, en otras, los excluidos buscaron alternativas para asociarse a las matrices alemanas.

El actor más gris fue la Administración germana, que llegó tarde y desinformada al proceso. Pero no hay que subestimar su papel, pues, además del pago por los bienes estatales y el oro incautado, consiguió lo que más interesaba a la industria germana: el derecho a la recompra y las promesas de liberalización de inversión extranjera en España. La proactividad de los expropiados, el "milagro alemán" y las expectativas que despertaba el mercado español hicieron innecesario lo demás.

El papel desempeñado por los Aliados en este proceso ha sido sin duda el mejor atendido por la historiografía. Nuestro estudio ha corroborado las tesis de Collado y de Martín Aceña. La CCA no tuvo ningún control sobre el proceso de expropiación en España, siendo sus quejas hábilmente acalladas desde la CEBE. Razones comerciales y geoestratégicas, además, recomendaron no ejercer más presión, ni sobre España ni sobre el resto de los países neutrales. Pero esto no significaba que los Aliados estuvieran satisfechos. Las siguientes palabras del representante americano en el CCA, Kasper, a principios de 1950, a propósito de la adjudicación del BAT, son significativas: "sin lugar a dudas aparecerán más casos [similares], y dada la reticencia española a intervenir sobre evidentes tapaderas, deudas comerciales, propiedades inmuebles, saldos bancarios, títulos mobiliarios, etc., llegará un momento en que una feroz, y más efectiva, campaña de protesta sea factible" ${ }^{\prime 67}$. Para desilusión aliada, ese momento nunca llegó. La misión que se les había encomendado a Kasper y al resto de los representantes aliados resultó imposible de cumplir. 


\section{Fuentes}

Archivo General de la Administración (AGA)

Archivo del Ministerio de Asuntos Exteriores (AMAE)

Bayer Archiv Leverkusen (BAL)

Bundesarchiv (BA)

Deutsche Handelskammer für Spanien, Madrid (DHK MAD)

Deutsches Technik Museum Berlin (DTMB)

Firmenarchiv der Hoechst (FAH)

Fondo del Banco Urquijo (FBU)

National Archives and Records Administration (NARA)

Politisches Archiv des Auswärtiges Amts (AA)

\section{Bibliografía}

Anuario Financiero y de Sociedades Anónimas de España, Madrid, Sopec.

COLLADO SEIDEL, Carlos (2001): Angst vor dem "Vierten Reich". Die Alliierten und die Ausschaltung des deutschen Einflusses in Spanien 1944-1958, Paderborn-MünchenWien-Zürich, Ferdinand Schöningh.

-(2005): España, refugio nazi, Madrid, Temas de Hoy.

Estadística del Comercio Exterior de España, Madrid, Ministerio de Hacienda.

DELAUNAY, Jean-Marc (1989): "La liquidation des avoirs allemands en Espagne (1945-1961)", en ETIENVRE, Jean Pierre, y URQUIJO, José Ramón (eds.), España, Francia y la Comunidad Europea, Casa de Velázquez/CSIC, Madrid, pp. 219-237.

DIENEL, Hans-Liudger (2004): Linde. History of a Technology Corporation, 1879-2004, Hampshire, Palgrave MacMillan.

FELDMAN, Gerald D. (2001): Allianz and the German Insurance Business, 1933-1945, Cambridge, Cambridge University Press.

FRAX, Esperanza, y MATILLA, María Jesús (1998): “Estudio de las compañías de seguros alemanas en España", en MARTíN ACEÑA, Pablo (dir.), Informe para la Comisión de investigación de las transacciones de oro procedente del Tercer Reich durante la Segunda Guerra Mundial (R. D. 1131/1997, de 11 de julio), Madrid, Ministerio de Asuntos Exteriores.

GARCÍA PÉREZ, Rafael (1994): Franquismo y Tercer Reich. Las relaciones económicas hispano-alemanas durante la Segunda Guerra Mundial, Madrid, Centro de Estudios Constitucionales.

KOBRAK, Christopher (2002): National Cultures and International Competition. The Experience of Schering A.G., 1851-1950, Cambridge, Cambridge University Press. 
LEITZ, Christian (1996): Economic Relations between Nazi Germany and Franco's Spain, 1936-1945, Oxford, Clarendon Press.

LOSCERTALES, Javier (2002): Deutsche Investitionen in Spanien 1870-1920, Stuttgart, Franz Steiner Verlag.

MARTÍN ACEÑA, Pablo (2001): El oro de Moscú y el oro de Berlín, Madrid, Taurus.

MARTÍN ACEÑA, Pablo, con la colaboración de MARTÍNEZ RUIZ, Elena; MARTORELL, Miguel, y MORENO, Begoña (2001): Los movimientos de oro en España durante la Segunda Guerra Mundial, Madrid, Ministerio de Asuntos Exteriores.

PONS, Jerònia (2002): Las estrategias de crecimiento de las compañias de seguros en España (1900-1940), Documento de Trabajo 2002/1, Fundación Empresa Pública.

PUIG RAPOSO, Núria (1999): "El crecimiento asistido de la industria química en España: Fabricación Nacional de Colorantes y Explosivos", Revista de Historia Industrial, 15, pp. 105-136.

-(2003): Bayer, Cepsa, Puig, Repsol, Schering y La Seda. Constructores de la química española, Madrid, Lid Editorial.

-(2004): "Auslandsinvestitionen ohne Technologietransfer? Die deutsche Chemieindustrie in Spanien (1897-1965)", en PETRI, Rolf (ed.), Technologietransfer aus der deutschen Chemieindustrie c.1920-c.1960, Berlin, Duncker \& Humblot, pp. 291-322.

-(2005): “La conexión alemana: redes empresariales hispano-alemanas en la España del siglo XX", ponencia presentada en el X Simposio de Historia Económica (Bellaterra, 27-29 enero 2005) y en el VIII Congreso de la Asociación Española de Historia Económica (Santiago de Compostela, 13-19 septiembre 2005).

-(2006): "Federico, José, Francisco y Enrique Lipperheide Henke", en TORRES, Eugenio (dir.), Cien empresarios vascos, Madrid, Lid Editorial (en prensa).

PUIG, Núria y LOSCERTALES, Javier (2001): “Las estrategias de crecimiento de la industria química alemana en España, 1880-1936: exportación e inversión directa", Revista de Historia Económica, XIX, 2, pp. 345-382.

Statistisches Reichsamt: Statistisches Jahrbuch für das Deutsche Reich.

US DEPARTMENT OF STATE (1997): Preliminary Study on US and Allied Efforts to Recover and Restore Gold and Other Assets Stolen or Hidden by Germany during World War II, Washington DC (http://www.state.gov/www/regions/eur/holocausthp.html).

-(1998): US and Allied Wartime and Postwar Relations and Negotiations with Argentina, Portugal, Spain, Sweden, and Turkey on Looted Gold and German External Assets and US Concerns About the Fate of the Wartime Ustasha Treasury, Washington DC (http://www.state.gov/www/regions/eur/holocausthp.html).

VIÑAS, Ángel (2001): Franco, Hitler y el estallido de la guerra civil. Antecedentes y consecuencias, Madrid, Alianza.

WEBER, Petra-Maria (1992): Spanische Deutschlandpolitik 1945-1958, Saabrücken-Fort Lauderdale, Breitenbach. 


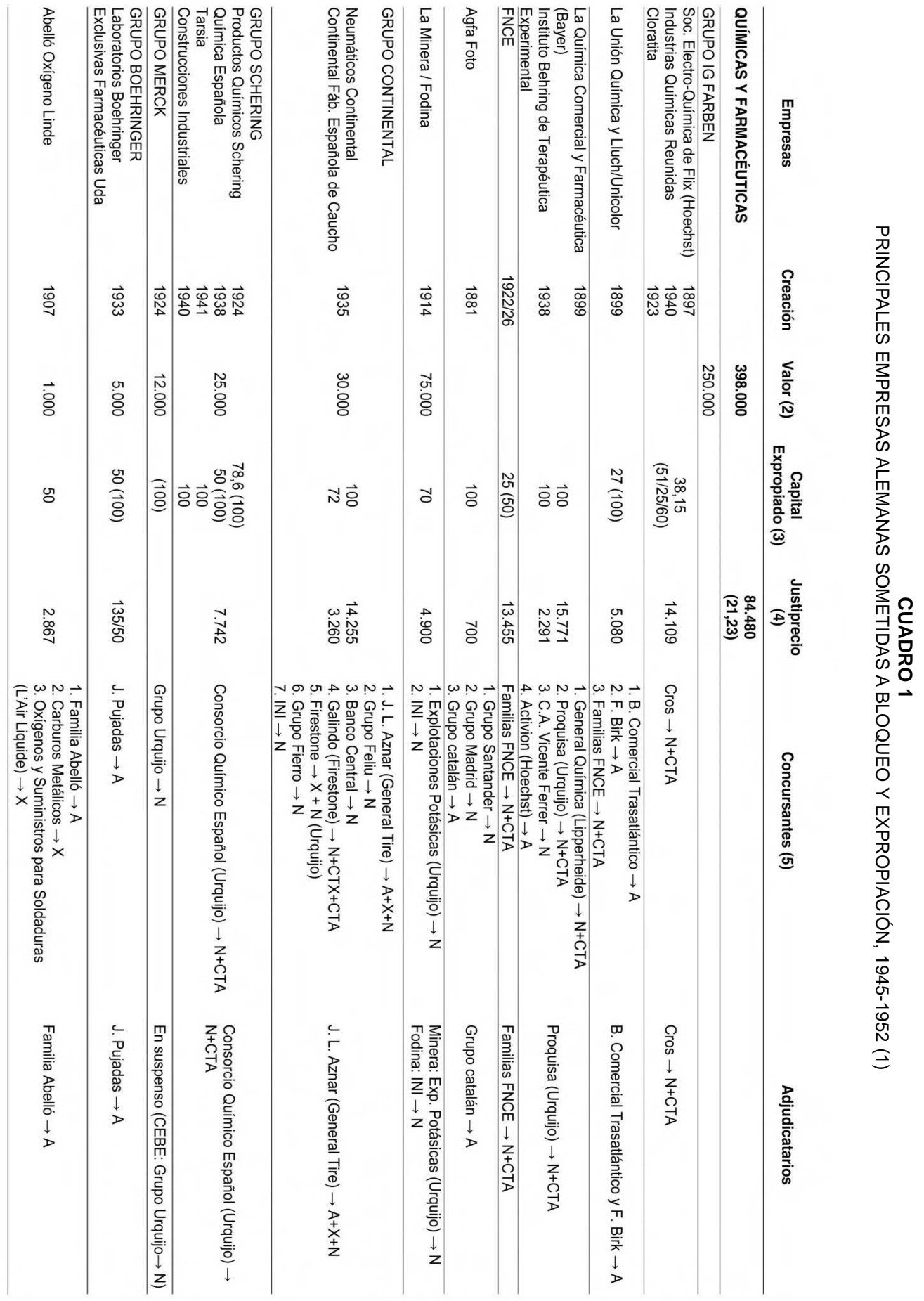




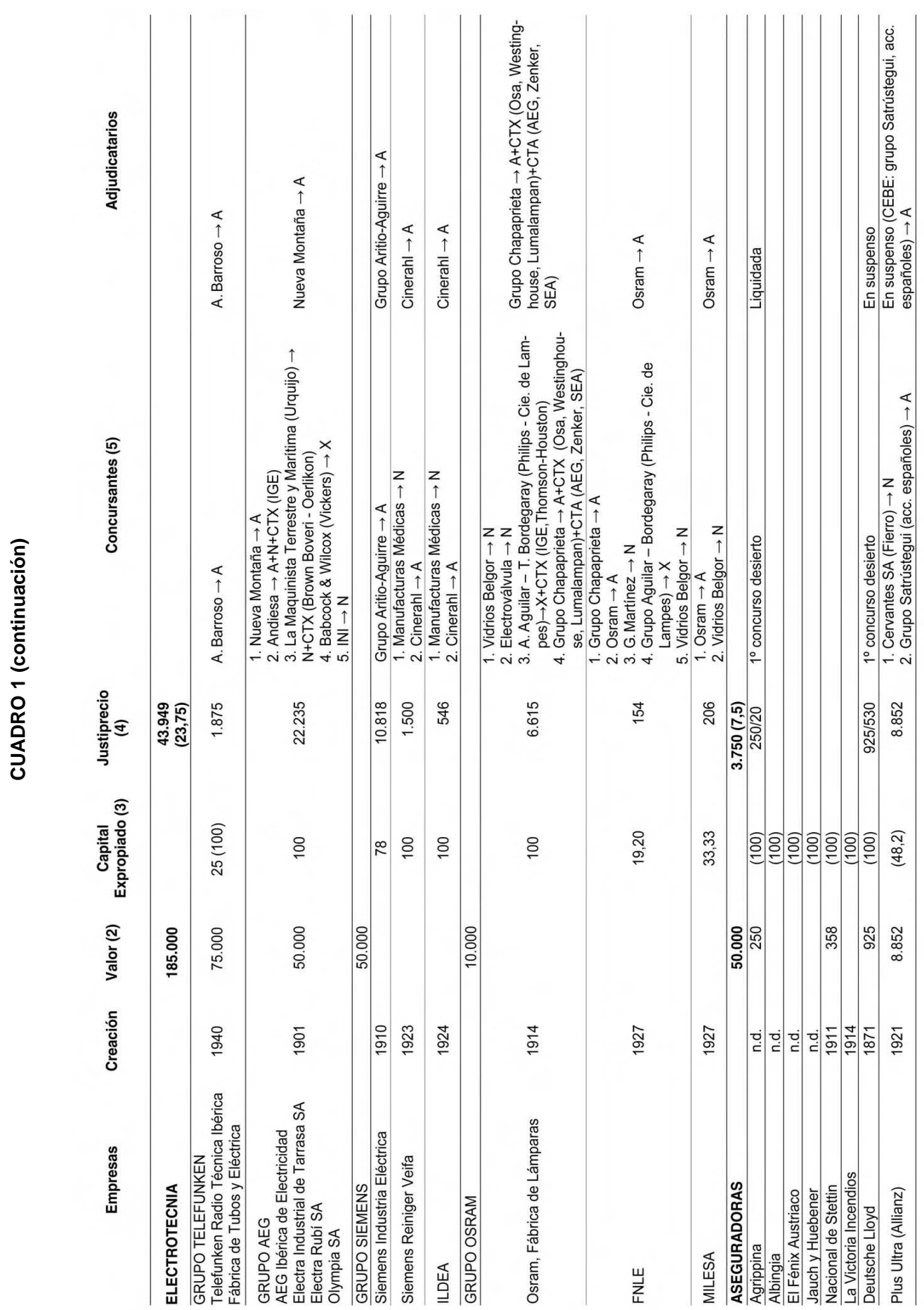



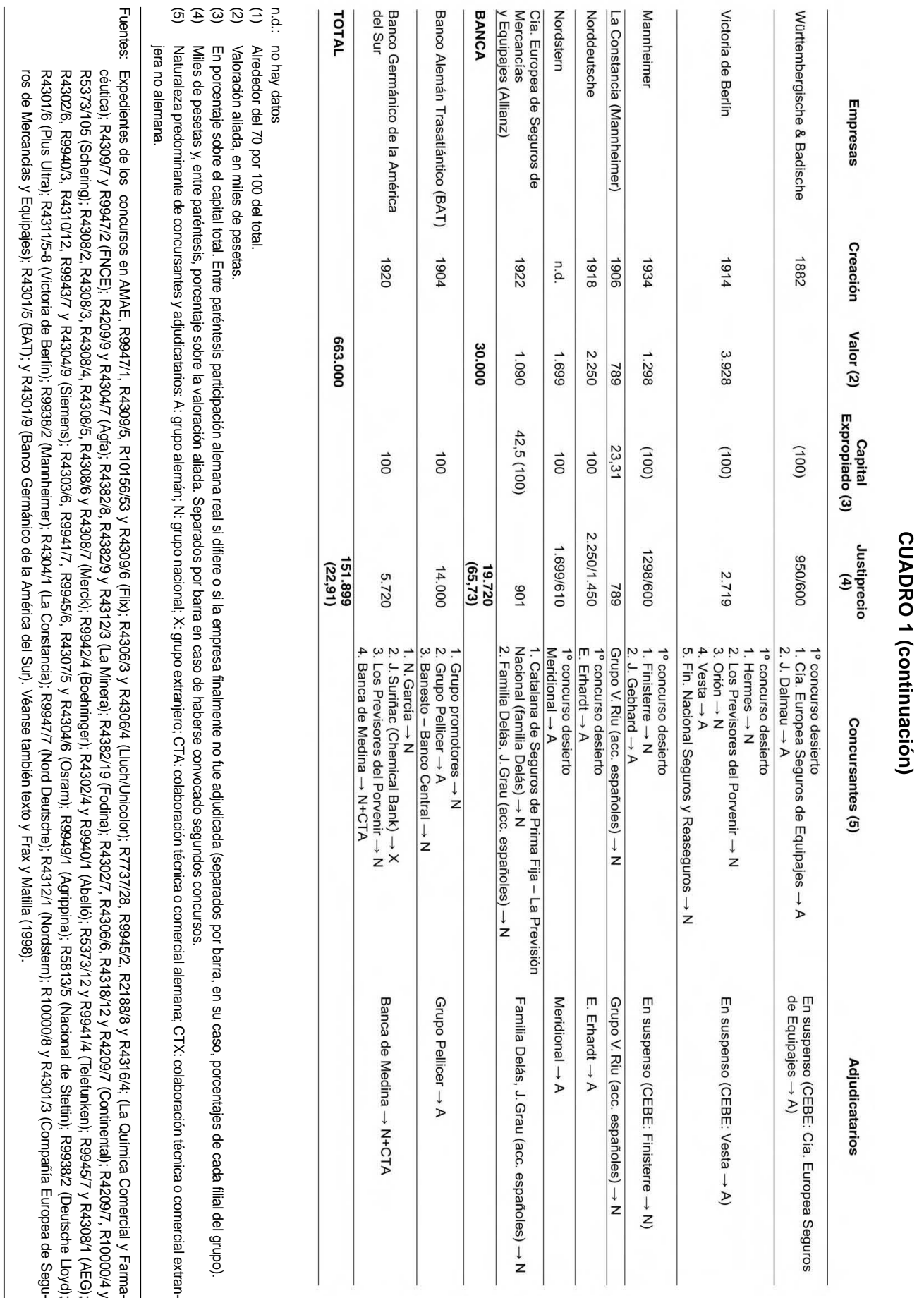


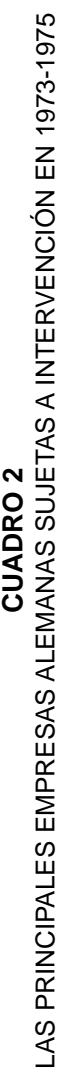

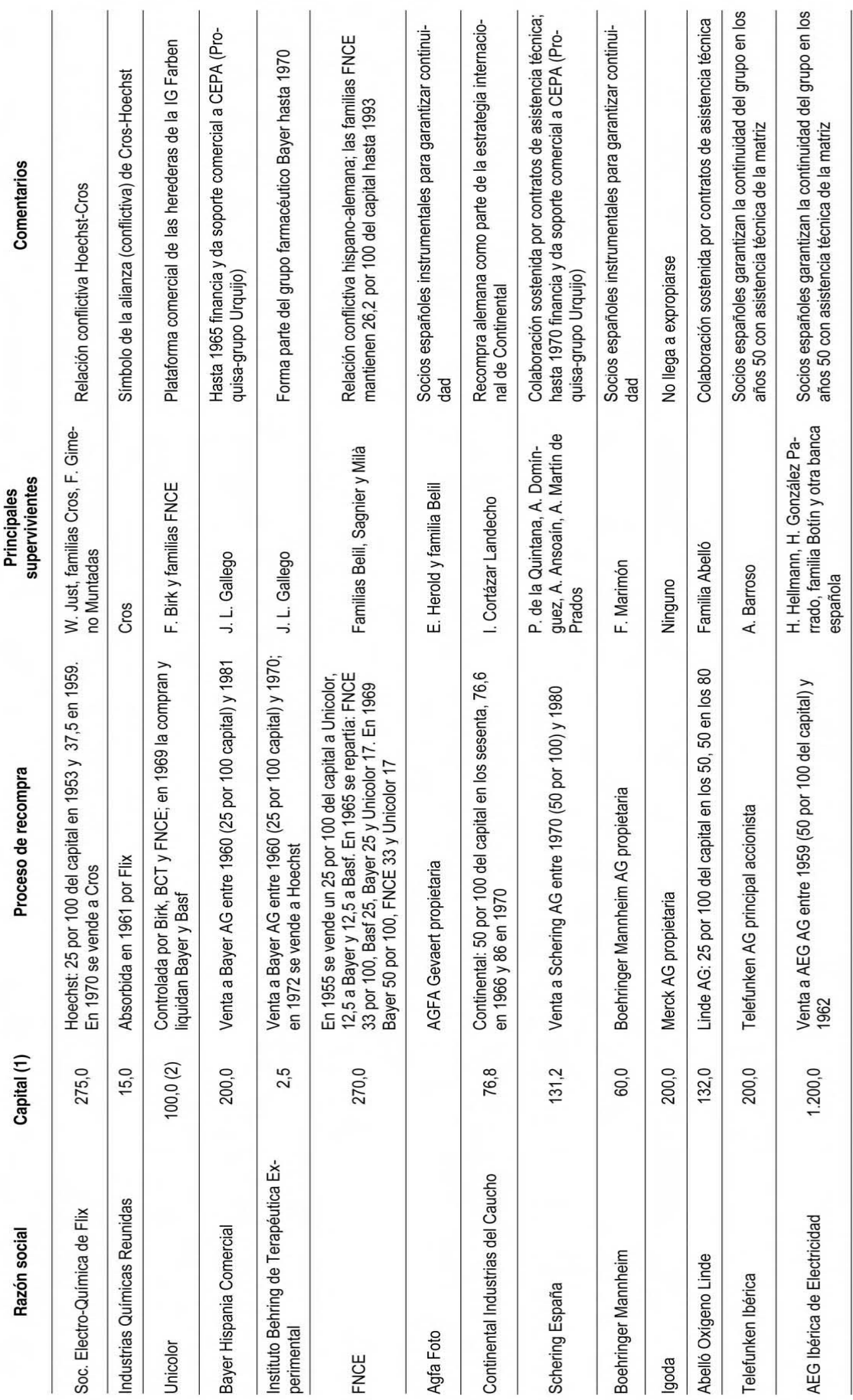




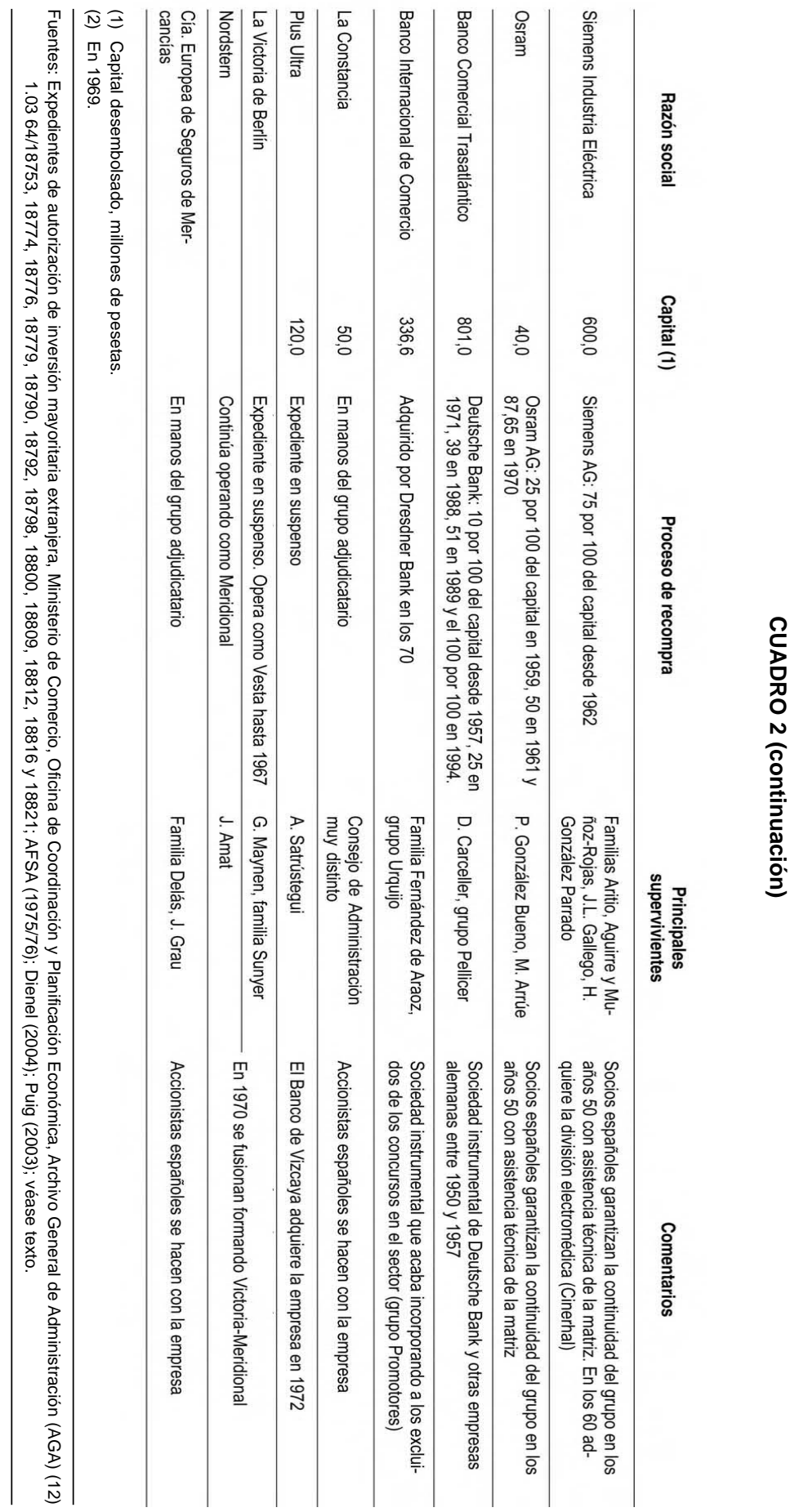

